\title{
Solvent Extraction of Divalent Metal Ions with Azacrown Ether Substituted Acylpyrazolones
}

\author{
Kensuke Kurahashi, Shigeo Umetani, ${ }^{\dagger}$ and Yoshiki Sohrin \\ Institute for Chemical Research, Kyoto University, Uji, Kyoto 611-0011, Japan
}

\begin{abstract}
Novel 4-acyl-5-pyrazolones having aza-15-crown-5 (HPMP-A15C5) and aza-18-crown-6 (HPMP-A18C6) moieties as an intramolecular synergist have been synthesized by simple coupling reactions between 1-phenyl-3-methyl-4-chloroacetyl5-pyrazolone and the corresponding azacrown ethers. The solvent extraction of the divalent metal ions $\left(\mathrm{Mn}^{2+}, \mathrm{Co}^{2+}, \mathrm{Ni}^{2+}\right.$, $\mathrm{Cu}^{2+}, \mathrm{Zn}^{2+}, \mathrm{Cd}^{2+}$ and $\mathrm{Pb}^{2+}$ ) were examined. Synergistic extractions with 1-phenyl-3-methyl-4-benzoyl-5-pyrazolone (HPMBP) and benzocrown ethers were also examined for a comparison. Extractions with the novel acylpyrazolones were unique and quite different from those with HPMBP and benzocrown ethers. The synergistic effect with benzocrown ethers was low, and an obvious difference brought by the ring size was not observed. The extractions of the divalent metal ions with HPMP-A18C6 were generally enhanced, as compared to those alone with HPMBP; on the contrary, the extractions with HPMP-A15C5 were relatively poor.
\end{abstract}

(Received October 4, 2007; Accepted November 20, 2007; Published February 10, 2008)

\section{Introduction}

Solvent extraction is known to be a very effective and selective separation method for metal ions. ${ }^{1-4}$ Acylpyrazolones are powerful chelating reagents, and have been used for the solvent extraction of metal ions. ${ }^{5-7}$ In the solvent extraction of metal ions with chelating reagents, such as acylpyrazolones, the extractability mainly depends on the stability of the complex formation of the chelating reagent and the metal ion.

Macrocyclic ligands, such as crown ethers and cryptands, have been utilized in metal-ion separations. ${ }^{8}$ Many novel macrocyclic ligands have been prepared as ion-pair extraction reagents, exhibiting excellent separation ability. ${ }^{9}$ It was shown that water soluble macrocyclic ligands could enhance the separability when they were added in the aqueous phase as ionsize selective masking reagents in the extraction of alkali, alkaline earth and lanthanide metal ions with the chelate extraction reagents. ${ }^{10,11}$ On the contrary, it is known that neutral macrocyclic ligands can work as synergists when they were added in the organic phase. In both cases, unique separability would be expected, since the selectivity of the macrocyclic ligands and the chelating reagents is quite different. In this regard, a reagent which has an acylpyrazolone unit and a crown ether unit in the same structure is expected to show unique selectivity. Although a large number of crown ethers bearing pendant groups have been synthesized, ${ }^{12,13}$ only a few examples of crown ether-bearing chelating reagents have been reported. ${ }^{14,15}$ In the present work, novel acylpyrazolones, HPMP-A15C5 and HPMP-A18C6 (Fig. 1) were prepared and the extractions of seven divalent metal ions $\mathrm{Mn}^{2+}, \mathrm{Co}^{2+}, \mathrm{Ni}^{2+}, \mathrm{Cu}^{2+}, \mathrm{Zn}^{2+}, \mathrm{Cd}^{2+}$ and $\mathrm{Pb}^{2+}$ ) were examined. The results were compared with those of the synergistic extractions using benzocrown ethers as synergistic reagents.

$\dagger$ To whom correspondence should be addressed.

E-mail: umetani@scl.kyoto-u.ac.jp

\section{Experimental}

\section{Chemicals and apparatus}

1-Aza-15-crown-5, 1-aza-18-crown-6, benzo-15-crown-5 (B15C5) and benzo-18-crown-6 (B18C6) were purchased commercially from Tokyo Kasei, and 1-phenyl-3-methyl-4chloroacetyl-5-pyrazolone was synthesized according to the literature. ${ }^{16}$ Good's buffers were purchased commercially from Nacalai Tesque. Metal solutions were prepared from standard solutions provided by Wako. These were used without further purification. Other chemicals were of reagent-grade materials. Water was demineralized and distilled.

The metal-ion concentrations were measured with a Japan Jarrell Ash Model ICAP-500 inductively coupled argon plasma atomic emission spectrophotometer. $\mathrm{pH}$ measurements were made with a Hitachi-Horiba F-8L pH meter equipped with Horiba 6028 glass combination $\mathrm{pH}$ electrode. The $\mathrm{pH}$ meter was calibrated against standard reference buffers. ${ }^{1} \mathrm{H}-\mathrm{NMR}$ spectra were measured with a JEOL JNM-AL300 spectrometer
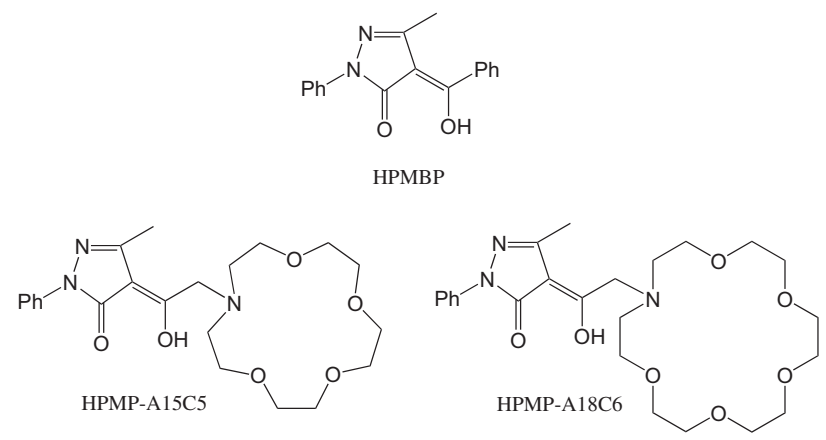

Fig. 1 HPMBP and azacrown ether substituted acylpyrazolones (HPMP-A15C5 and HPMP-A18C6). 
(300 MHz) in $\mathrm{CDCl}_{3}$. The extractions were performed in $30 \mathrm{ml}$ centrifuge tubes with the aid of a Taitek Bio-shaker type BR$30 \mathrm{~L}$ thermostated at $25^{\circ} \mathrm{C}$.

\section{Synthesis}

$N-\left[\left(5^{\prime}-\right.\right.$ Hydroxy-3'-methyl-1'-phenylpyrazolol-4' -yl)carbonylmethyl]-1,4,7,10-tetraoxa-13-azacyclopentadecane (HPMPA15C5). After 1-aza-15-crown-5 (0.878 g) and 1-phenyl-3methyl-4-chloroacetyl-5-pyrazolone $(1.00 \mathrm{~g})$ were dissolved in $50 \mathrm{ml}$ of acetonitrile, cesium carbonate $(2.61 \mathrm{~g})$ was added and the mixture was refluxed for one day under a nitrogen atmosphere. Chloroform $(200 \mathrm{ml})$ was added to the reaction mixture, and the organic phase was washed several times with water. After drying over sodium sulfate, chloroform was evaporated in vacuo to afford the product. Yield, 58.3\%; HRMS $m / z, 433.2223$ (calcd for $\mathrm{C}_{22} \mathrm{H}_{31} \mathrm{~N}_{3} \mathrm{O}_{6}: 433.2213$ ); $\delta_{\mathrm{H}}$ NMR (300 MHz, $\left.\mathrm{CDCl}_{3}\right), 2.55(3 \mathrm{H}, \mathrm{Me}), 3.19-3.84(20 \mathrm{H}$, crown $), 3.91\left(2 \mathrm{H}, \mathrm{NCH}_{2} \mathrm{C}=\mathrm{O}\right), 7.21(1 \mathrm{H}, p-\mathrm{H}$ of $\mathrm{NPh}), 7.40(2 \mathrm{H}$, $m-\mathrm{H}$ of $\mathrm{NPh}), 7.81(2 \mathrm{H}, o-\mathrm{H}$ of $\mathrm{NPh})$; Found $(\mathrm{H}, 7.17$; C, 60.21; $\mathrm{N}, 9.48 \%)$; Calcd (H, 7.21; C, 60.95; N, 9.69\%).

$N-\left[\left(5^{\prime}-\right.\right.$ Hydroxy-3'-methyl- $1^{\prime}$-phenylpyrazolol-4'-yl)carbonylmethyl]-1,4,7,10,13-pentaoxa-16-azacyclooctadecane (HPMPA18C6). After 1-aza-18-crown-6 (1.06 g) and 1-phenyl-3methyl-4-chloroacetyl-5-pyrazolone (1.52 g) were dissolved in $4 \mathrm{ml}$ of ethanol; $1.1 \mathrm{ml}$ of triethylamine was added, and the mixture was refluxed for one day under a nitrogen atmosphere. The reaction mixture was poured into $100 \mathrm{ml}$ of water and extracted with chloroform. The organic layer was dried (sodium sulfate) and evaporated in vacuo. The residue was purified by a silica-gel column chromatography, eluting with a mixture of chloroform and methanol (9:1) to afford the product. Yield, 83.3\%; HRMS $\mathrm{m} / \mathrm{z}, 477.2494$ (calcd for $\mathrm{C}_{24} \mathrm{H}_{35} \mathrm{~N}_{3} \mathrm{O}_{7}$ : 477.2475); $\delta_{\mathrm{H}} \mathrm{NMR}\left(300 \mathrm{MHz}, \mathrm{CDCl}_{3}\right), 2.39(3 \mathrm{H}, \mathrm{Me}), 3.34-$ $3.84(24 \mathrm{H}$, crown $), 4.29\left(2 \mathrm{H}, \mathrm{NCH}_{2} \mathrm{C}=\mathrm{O}\right), 7.08(1 \mathrm{H}, p-\mathrm{H}$ of $\mathrm{NPh})$, 7.32(2H, $m-\mathrm{H}$ of NPh), 7.89(2H, $o-\mathrm{H}$ of NPh); Found (H, 6.46; C, 54.87; N, 8.68\%); Calcd (H, 7.39; C, 60.36; N, 8.80\%).

\section{Solvent extraction of divalent metal ions}

A $5 \mathrm{ml}$ portion of an aqueous phase containing $0.1 \mathrm{mM}(1 \mathrm{M}$ $=1 \mathrm{~mol} \mathrm{dm}^{-3}$ ) metal ion, $0.1 \mathrm{M}$ tetramethylammonium chloride to keep the ionic strength at 0.1 , and $0.01 \mathrm{M}$ Good's buffer was adjusted to the desired $\mathrm{pH}$ with nitric acid and tetramethylammonium hydroxide solution. 2-Morpholinoethanesulfonic acid, monohydrate (MES) was used for $\mathrm{pH}$ below 7.0, 3-morpholinopropanesulfonic acid (MOPS) for $\mathrm{pH} 6.5$ - 8.0 and $\mathrm{N}$-tris(hydroxymethyl)methyl-3-aminopropanesulfonic acid (TAPS) for $\mathrm{pH}$ over 8.0. Sodium acetate was used as a buffering reagent in the lower $\mathrm{pH}$ region. Tetramethylammonium chloride was not added for $\mathrm{Pb}^{2+}$ to avoid precipitation. The aqueous phase was mixed with an equal volume of a chloroform phase containing the required amount of the chelating ligands and crown ethers, and the mixture was shaken at $25^{\circ} \mathrm{C}$ for over $2 \mathrm{~h}$ until the reaction reached to equilibrium. After centrifugation, the $\mathrm{pH}$ value of the aqueous phase was measured and taken as the equilibrium value. The metal concentration in the aqueous phase was determined by ICP-AES. That in the organic phase was measured in the same way after back-extraction by stripping with a nitric acid solution. The sum of the metal concentrations in the two phases agreed well with the initial concentration.

\section{Results and Discussion}

Synergistic extraction with HPMBP and benzocrown ether In the extraction of the divalent metal ions $\left(\mathrm{M}^{2+}\right)$ with HPMBP
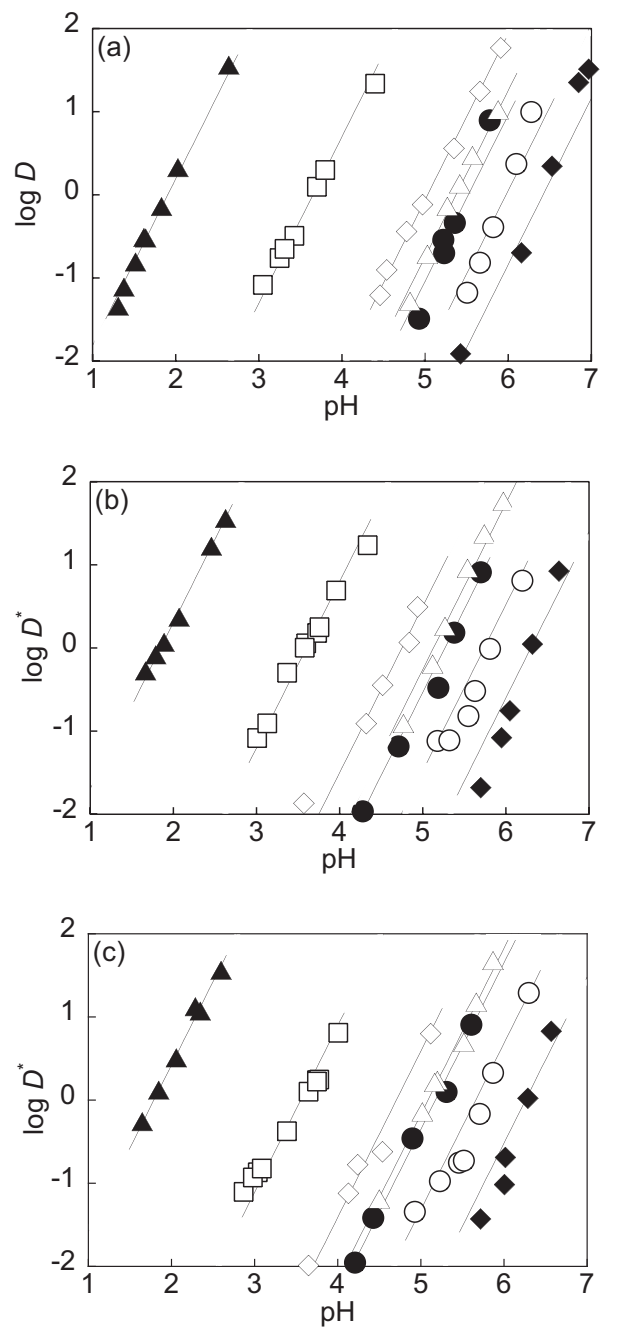

Fig. 2 Extraction of the divalent metal ions into chloroform with HPMBP in the absence (a) and presence of benzocrown ether, B15C5 (b) and B18C6 (c). (a) $[\mathrm{HPMBP}]_{\mathrm{o}}=0.01 \mathrm{M}$, (b) $[\mathrm{HPMBP}]_{0}=$ $[\mathrm{B} 15 \mathrm{C} 5]_{\mathrm{o}}=0.01 \mathrm{M}$, (c) $[\mathrm{HPMBP}]_{\mathrm{o}}=[\mathrm{B} 18 \mathrm{C} 6]_{\mathrm{o}}=0.01 \mathrm{M} . \mathrm{O}, \mathrm{Mn}^{2+}$; $\bullet, \mathrm{Co}^{2+} ; \triangle, \mathrm{Ni}^{2+} ; \boldsymbol{\triangle}, \mathrm{Cu}^{2+} ; \diamond, \mathrm{Zn}^{2+} ; \diamond, \mathrm{Cd}^{2+} ; \square, \mathrm{Pb}^{2+}$.

(HA), the overall extraction equilibrium and the extraction constant, $K_{\mathrm{ex}}$, can be written as follows:

$$
\begin{aligned}
& \mathrm{M}^{2+}+2 \mathrm{HA}_{\mathrm{o}} \rightleftharpoons \mathrm{MA}_{2, \mathrm{o}}+2 \mathrm{H}^{+}, \\
& K_{\mathrm{ex}}=\left[\mathrm{MA}_{2}\right]_{\mathrm{o}}\left[\mathrm{H}^{+}\right]^{2} /\left[\mathrm{M}^{2+}\right][\mathrm{HA}]_{\mathrm{o}}^{2}=D\left[\mathrm{H}^{+}\right]^{2} /[\mathrm{HA}]_{\mathrm{o}}^{2},
\end{aligned}
$$

where subscript o denotes the species in the organic phase and $D\left(\left[\mathrm{MA}_{2}\right]_{0} /\left[\mathrm{M}^{2+}\right]\right)$ is the distribution ratio of $\mathrm{M}^{2+}$. Figure $2 \mathrm{a}$ shows plots of $\log D v s . \mathrm{pH}$ in the extraction of divalent metal ions with 0.01 M HPMBP in chloroform. The plots are straight lines with a slope very close to 2 , indicating that two molecules of HPMBP react with one molecule of $\mathrm{M}^{2+}$, releasing two molecules of hydrogen. The $\mathrm{pH}_{1 / 2}$ values, at which half the metal ions are extracted, read from the plots of $\log D v s$. $\mathrm{pH}$ for each divalent metal ion, were employed to obtain $K_{\text {ex }}$ on the basis of Eq. (2). The $\log K_{\text {ex }}$ values are given in Table 1. The divalent metal ions were extracted in the order $\mathrm{Cu}^{2+}>\mathrm{Pb}^{2+}>$ $\mathrm{Zn}^{2+}>\mathrm{Ni}^{2+}>\mathrm{Co}^{2+}>\mathrm{Mn}^{2+}>\mathrm{Cd}^{2+}$. The extraction order agrees with the Irving-Williams series $\left(\mathrm{Zn}^{2+}<\mathrm{Cu}^{2+}>\mathrm{Ni}^{2+}>\mathrm{Co}^{2+}>\right.$ $\left.\mathrm{Fe}^{2+}>\mathrm{Mn}^{2+}\right)$. The extraction of $\mathrm{Cd}^{2+}$ is low because of its large ionic radius. 
Table 1 Extraction and adduct formation constants

\begin{tabular}{lrrrrrrr}
\hline & $\mathrm{Mn}^{2+}$ & $\mathrm{Co}^{2+}$ & $\mathrm{Ni}^{2+}$ & $\mathrm{Cu}^{2+}$ & $\mathrm{Zn}^{2+}$ & $\mathrm{Cd}^{2+}$ & $\mathrm{Pb}^{2+}$ \\
\hline $\log K_{\text {ex }}{ }^{\mathrm{a}}$ & -7.95 & -7.04 & -6.75 & 0.19 & -6.06 & -8.66 & -3.30 \\
$\log \beta_{\mathrm{s}}(\mathrm{B} 15 \mathrm{C} 5)$ & 2.10 & 2.23 & 1.83 & 0.71 & 1.98 & 1.77 & 1.67 \\
$\log \beta_{\mathrm{s}}(\mathrm{B} 18 \mathrm{C} 6)$ & 2.36 & 2.37 & 1.93 & 1.39 & 1.82 & 1.97 & 1.83 \\
\hline
\end{tabular}

a. Extractions into chloroform at $25^{\circ} \mathrm{C}$.
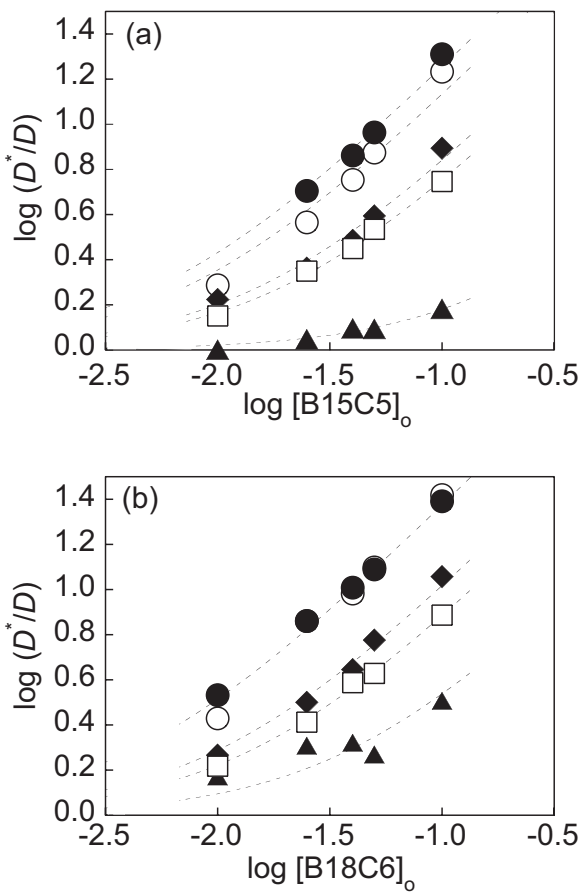

Fig. 3 Plots of $\log \left(D / D^{*}\right)$ vs. $\log [\mathrm{B} 15 \mathrm{C} 5]_{\mathrm{o}}$ (a) and $\log [\mathrm{B} 18 \mathrm{C} 6]_{\mathrm{o}}$ (b) $\bigcirc, \mathrm{Mn}^{2+} ; \bullet, \mathrm{Co}^{2+} ; \boldsymbol{\Delta}, \mathrm{Cu}^{2+} ; \diamond, \mathrm{Cd}^{2+} ; \square, \mathrm{Pb}^{2+}$

Upon adding benzocrown ethers (CR) to the organic phase of the chelate extraction system, benzocrown ethers were not soluble in water, and attached to the metal acylpyrazolonate to form an $\mathrm{MA}_{2}(\mathrm{CR})_{\mathrm{s}}$ type of adduct, where $s$ indicates the number of the benzocrown ether in the adduct. Synergistic extractions of divalent metal ions were performed with 0.01 M HPMBP in the presence of $0.01 \mathrm{M} \mathrm{B} 15 \mathrm{C} 5$ or $\mathrm{B} 18 \mathrm{C} 6$, and are shown in Figs. $2 \mathrm{~b}$ and $2 \mathrm{c}$.

In the synergistic extraction of divalent metal ions in the presence of benzocrown ethers (CR), the distribution ratio, $D^{*}$, can be expressed as follows:

$$
D^{*}=\left\{\left[\mathrm{MA}_{2}\right]_{\mathrm{o}}+\left[\mathrm{MA}_{2}(\mathrm{CR})\right]_{\mathrm{o}}+\cdots+\left[\mathrm{MA}_{2}(\mathrm{CR})_{\mathrm{s}}\right]_{\mathrm{o}}\right\} /\left[\mathrm{M}^{2+}\right] \text {. }
$$

Dividing $D^{*}$ by $D$ gives

$$
D^{*} / D=1+\Sigma \beta_{\mathrm{s}}[\mathrm{CR}]_{\mathrm{o}}^{\mathrm{s}} \text {, }
$$

where $\beta_{\mathrm{s}}$ is an adduct formation constant, defined as $\left[\mathrm{MA}_{2}(\mathrm{CR})_{\mathrm{s}}\right]_{\mathrm{o}} /\left[\mathrm{MA}_{2}\right]_{\mathrm{o}}[\mathrm{CR}]_{\mathrm{o}}^{\mathrm{s}}$. In the higher $[\mathrm{CR}]_{\mathrm{o}}$ region, where $\mathrm{MA}_{2}(\mathrm{CR})_{\mathrm{s}}$ could be considered to be the predominant extracted species, the extraction equilibrium and the synergistic extraction constant, $K_{\mathrm{ex}, \mathrm{s}}$, are expressed as follows:

$$
\mathrm{M}^{2+}+2 \mathrm{HA}_{0}+s \mathrm{CR}_{\mathrm{o}} \rightleftharpoons \mathrm{MA}_{2}(\mathrm{CR})_{\mathrm{s}, \mathrm{o}}+2 \mathrm{H}^{+},
$$
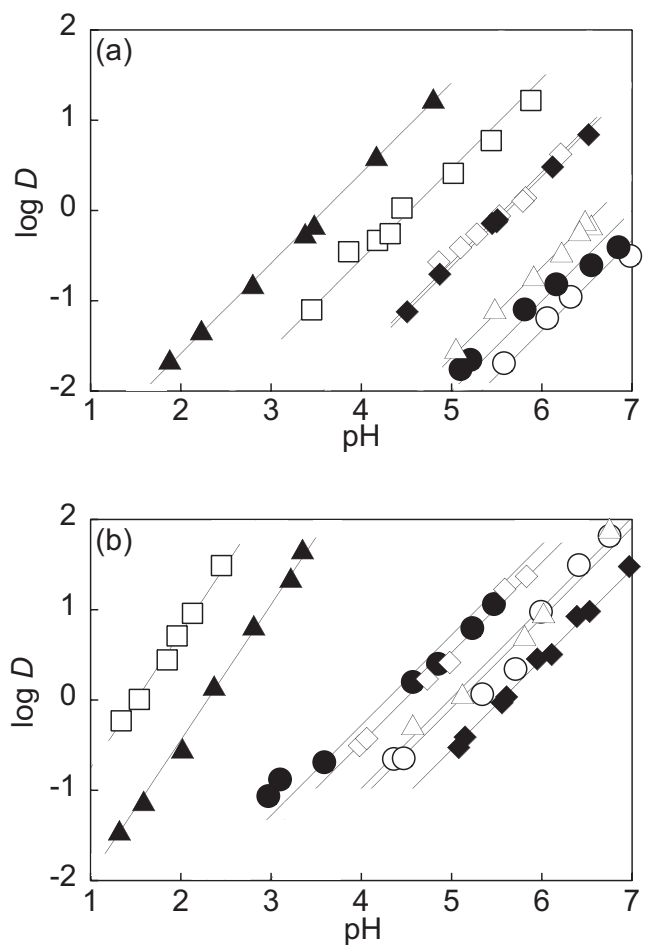

Fig. 4 Extraction of the divalent metal ions into chloroform with HPMP-A15C5 (a) and HPMP-A18C6 (b). (a) [HPMP-A15C5 $]_{0}=$ $0.01 \mathrm{M}$, (b) $[\text { HPMP-A18C6 }]_{\mathrm{o}}=0.01 \mathrm{M}$. Symbols are the same as those in Fig. 2.

$$
\begin{aligned}
K_{\text {ex }, \mathrm{s}} & =\left[\mathrm{MA}_{2}(\mathrm{CR})_{\mathrm{s}}\right]_{\mathrm{o}}\left[\mathrm{H}^{+}\right]^{2} /\left[\mathrm{M}^{2+}\right][\mathrm{HA}]_{\mathrm{o}}^{2}[\mathrm{CR}]_{\mathrm{o}}^{\mathrm{s}} \\
& =D\left[\mathrm{H}^{+}\right]^{2} /[\mathrm{HA}]_{\mathrm{o}}^{2}[\mathrm{CR}]_{0}^{\mathrm{s}} .
\end{aligned}
$$

The number of $\mathrm{CR}$ in the extracted species and the adduct formation constants can be obtained by treating the $\log \left(D^{*} / D\right)$ vs. $\log [\mathrm{CR}]_{\mathrm{o}}$ plots according to Eq. (4).

Figures $3 \mathrm{a}$ and $3 \mathrm{~b}$ show $\log \left(D^{*} / D\right)$ vs. $\log [\mathrm{CR}]_{\mathrm{o}}$ plots for the extraction of the divalent metal ions. The slope of the straight portion in the higher CR concentration is about 1 , and decreases at the lower $\mathrm{CR}$ concentration, indicating that the extracted species with HPMBP and $\mathrm{B} 15 \mathrm{C} 5$ or $\mathrm{B} 18 \mathrm{C} 6$ are $\mathrm{MA}_{2}(\mathrm{CR})$. The adduct formation constants were calculated by a non-linear least-squares method on the basis of Eq. (4), and are summarized in Table 1.

The adduct formation constants for the benzocrown ethers are much lower than those for trioctylphosphine oxide and bidentate phosphine oxide compounds. ${ }^{17}$ The adduct formation constants for B15C5 and B18C6 are similar. No significant difference that arises from the structure of the crown ethers is observed. Two molecules of HPMBP react with one molecule of $\mathrm{M}^{2+}$ to form the $\mathrm{MA}_{2}$-type complex. It could be difficult that five or six oxygen atoms in the benzocrown ethers coordinate fully to the central metal ion in $\mathrm{MA}_{2}$. This could be the reason why the adduct formation constants are small and similar. The low basicity of the donating oxygens in the crown ethers should also be taken into consideration.

\section{Extraction with azacrown ether substituted acylpyrazolones}

The divalent metal ions were extracted into chloroform with 0.01 M HPMP-A15C5 or HPMP-A18C6, and the results are shown in Figs. 4a and 4b. As can be seen in the figures, the plots are straight lines with a slope about 1 for all of the metal ions in Fig. 4a. The slope is about 1.5 for $\mathrm{Cu}^{2+}$ and $\mathrm{Pb}^{2+}$ and 1 
Table $2 \mathrm{pH}_{1 / 2}$ values in the extraction of divalent metal ions

\begin{tabular}{|c|c|c|c|c|c|c|c|c|c|c|}
\hline & \multirow{2}{*}{$\frac{\text { HPMBP }}{\mathrm{pH}_{1 / 2}^{\mathrm{b}}}$} & \multicolumn{2}{|c|}{ HPMP-A15C5 } & \multicolumn{2}{|c|}{ HPMP-A18C6 } & \multicolumn{2}{|c|}{ HPMBP + B15C5 } & \multicolumn{2}{|c|}{ HPMBP + B18C6 } & \multirow{2}{*}{$\begin{array}{c}\text { Ionic } \\
\text { radius }{ }^{2} / \AA\end{array}$} \\
\hline & & $\mathrm{pH}_{1 / 2}{ }^{\mathrm{c}}$ & $\Delta \mathrm{pH}_{1 / 2}$ & $\mathrm{pH}_{1 / 2}{ }^{\mathrm{c}}$ & $\mathrm{p} \Delta \mathrm{pH}_{1 / 2}$ & $\mathrm{pH}_{1 / 2}^{\mathrm{d}}$ & $\Delta \mathrm{pH}_{1 / 2}$ & $\mathrm{pH}_{1 / 2}{ }^{\mathrm{d}}$ & $\Delta \mathrm{pH}_{1 / 2}$ & \\
\hline $\mathrm{Mn}^{2+}$ & 5.94 & 7.33 & -1.39 & 5.09 & 0.85 & 5.74 & 0.20 & 5.66 & 0.28 & 0.80 \\
\hline $\mathrm{Co}^{2+}$ & 5.52 & 7.00 & -1.48 & 4.28 & 1.24 & 5.27 & 0.25 & 5.18 & 0.34 & 0.72 \\
\hline $\mathrm{Ni}^{2+}$ & 5.37 & 6.63 & -1.26 & 4.98 & 0.40 & 5.13 & 0.24 & 5.09 & 0.28 & 0.69 \\
\hline $\mathrm{Cu}^{2+}$ & 1.90 & 3.59 & -1.69 & 2.25 & -0.35 & 1.85 & 0.05 & 1.79 & 0.11 & 0.72 \\
\hline $\mathrm{Zn}^{2+}$ & 5.01 & 5.57 & -0.56 & 4.48 & 0.54 & 4.75 & 0.26 & 4.71 & 0.30 & 0.74 \\
\hline $\mathrm{Cd}^{2+}$ & 6.42 & 5.62 & 0.80 & 5.55 & 0.87 & 6.30 & 0.12 & 6.26 & 0.16 & 0.92 \\
\hline $\mathrm{Pb}^{2+}$ & 3.67 & 4.54 & -0.87 & 1.31 & 2.35 & 3.60 & 0.07 & 3.55 & 0.12 & 1.24 \\
\hline
\end{tabular}

a. Taken from Ref. 20. Ionic radius for a coordination number of 6. b. $[\mathrm{HPMBP}]_{0}=0.01 \mathrm{M}$. c. $[\mathrm{HPMP}-\mathrm{A} 15 \mathrm{C} 6]_{\mathrm{o}}=[\mathrm{HPMP}-\mathrm{A} 18 \mathrm{C} 6]_{\mathrm{o}}=$ $0.01 \mathrm{M}$. d. $[\mathrm{HPMBP}]_{0}=[\mathrm{CR}]_{0}=0.01 \mathrm{M}$ in chloroform.

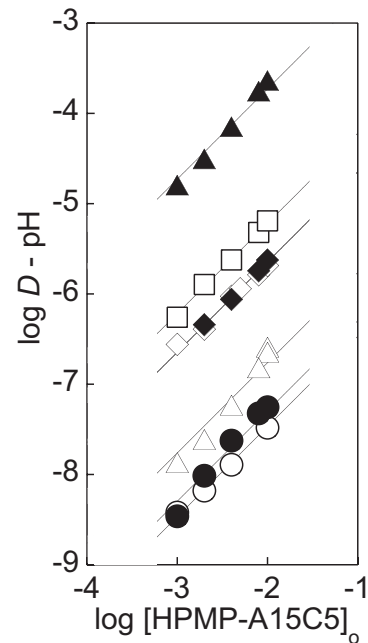

Fig. 5 Plots of $\log D-\mathrm{pH} v s . \log [$ HPMP-A15C5].. Symbols are the same as those in Fig. 2.

for the other metal ions in Fig. $4 \mathrm{~b}$. These results indicate that the extracted species is not a $\mathrm{MA}_{2}$-type complex, as seen in Eq. (1). The effect of the concentration of the extraction reagent was examined to clarify the extracted species. The $\log D$-pH vs. $\log [$ HPMP-A15C5]。 plots are shown in Fig. 5. The plots are straight lines with a slope about 1 . Similar results were obtained for HPMP-A18C6; however the slopes for $\mathrm{Cu}^{2+}$ and $\mathrm{Pb}^{2+}$ were about 1.5. These results indicate that the possible composition of the extracted species is MAX, where $\mathrm{X}$ is assumed to be an anion based on the neutrality of the extracted species. Some anions, such as perchlorate, nitrate and chloride, were added to the extraction system; however, the extraction behaviors did not change significantly. The composition of the extracted species with HPMP-A15C5 and HPMP-A18C6 was not determined clearly. The effect of the metal-ion concentration was also examined; however, the extraction behaviors did not show any significant change, indicating that the extracted species are not polynuclear complexes. The extracted species for $\mathrm{Cu}^{2+}$ and $\mathrm{Pb}^{2+}$ with HPMP-A18C6 (Fig. $4 \mathrm{~b})$ might be a mixture of $\mathrm{MA}_{2}$ and MAX.

The divalent metal ions were extracted in the order $\mathrm{Cu}^{2+}>$ $\mathrm{Pb}^{2+}>\mathrm{Cd}^{2+}>\mathrm{Zn}^{2+}>\mathrm{Ni}^{2+}>\mathrm{Co}^{2+}>\mathrm{Mn}^{2+}$, with HPMP-A15C5 and $\mathrm{Pb}^{2+}>\mathrm{Cu}^{2+}>\mathrm{Co}^{2+}>\mathrm{Zn}^{2+}>\mathrm{Ni}^{2+}>\mathrm{Mn}^{2+}>\mathrm{Cd}^{2+}$, with HPMP-A18C6. It is difficult to compare the extractability in the present work, for the extraction mechanism in each system is quite different. The $\mathrm{pH}_{1 / 2}$ values for each extraction system are summarized in Table 2. The reagent concentrations were fixed at $0.01 \mathrm{M}$ to make the comparison reasonable. The $\Delta \mathrm{pH}_{1 / 2}$ value stands for the difference in the $\mathrm{pH}_{1 / 2}$ value from that of the HPMBP system. The positive value indicates that the extraction was enhanced as compared with those of the HPMBP system. The $\Delta \mathrm{pH}_{1 / 2}$ values in the synergistic extraction (HPMBP + B15C5 and HPMBP + B18C6) systems are positive and small, as mentioned previously. No significant difference was observed among the metal ions.

The plots in Figs. $4 a, 4 b$ and 5 suggest the possibility that one molecule of the azacrown ether substituted acylpyrazolone reacts with one molecule of $\mathrm{M}^{2+}$. It could be considered that the MA complex can provide enough space for the crown ether moiety, unlike the case in the synergistic extraction. As can be seen in Table 2 , the $\Delta \mathrm{pH}_{1 / 2}$ values for HPMP-A15C5 are negative, except for that of $\mathrm{Cd}^{2+}$. The $\Delta \mathrm{pH}_{1 / 2}$ values for HPMPA18C6 are positive, except for that of $\mathrm{Cu}^{2+}$. Generally, the extractions with HPMP-A18C6 were enhanced, and those with HPMP-A15C5 were weakened, as compared to those with HPMBP. These results do not obey the complexation tendency for the crown ethers and the divalent metal ions. ${ }^{8,9,18,19}$ It was reported that the stability constants $(K)$ for the metal ion-crown ether complexes are generally small, even in a $40 \%$ (v/v) ethanol + water solution. ${ }^{18,19}$ The $\log K$ values of $15 \mathrm{C} 5$ for $\mathrm{Mn}^{2+}, \mathrm{Co}^{2+}, \mathrm{Ni}^{2+}, \mathrm{Cu}^{2+}, \mathrm{Zn}^{2+}$ and $\mathrm{Cd}^{2+}$ are similar $(1.7-2.1)$ and that for $\mathrm{Pb}^{2+}$ is slightly larger (2.8). The $\log K$ values of $18 \mathrm{C} 6$ for $\mathrm{Co}^{2+}, \mathrm{Ni}^{2+}, \mathrm{Cu}^{2+}$ and $\mathrm{Zn}^{2+}$ are similar $(1.6-1.8)$, those for $\mathrm{Mn}^{2+}$ (2.6) and $\mathrm{Cd}^{2+}(3.7)$ are slightly larger and that for $\mathrm{Pb}^{2+}$ (6.9) is much larger. The carbon chain length between the pyrazolone ring and the azacrown ether unit is not long enough. The enhanced extractions with HPMP-A18C6 could be caused by the larger ring size than that of HPMP-A15C5, which would make the oxygen atoms in the crown ether ring possible to readily approach the central metal ion. The most enhanced extraction was obtained for $\mathrm{Pb}^{2+}$ with HPMP-A18C6. It was found that $\mathrm{Pb}^{2+}$ was extracted at a much lower $\mathrm{pH}$ region than $\mathrm{Cu}^{2+}$.

\section{Conclusion}

The novel azacrown ether substituted acylpyrazolones, HPMPA15C5 and HPMP-A18C6, were synthesized, and the extractions of the divalent metal ions were examined. The synergistic extractions with HPMBP and benzocrown ethers were also examined. It was found that the synergistic effect with benzocrown ethers was low. The extracted species with HPMP-A15C5 and HPMP-A18C6 were not solved clearly. The enhanced extractions could be obtained with HPMP-A18C6, as compared to those with HPMBP. On the other hand, the 
extractions with HPMP-A15C5 were relatively poor. The results did not obey the complexation tendency reported for macrocyclic ligands and chelating ligands.

The synergistic extractions and those with the azacrown ether substituted acylpyrazolones in the present work are found to be quite different from the ion-pair extractions with macrocyclic ligands, such as crown ethers and cryptands. The difference can be explained by considering that the present extractions were made with chelating reagents and macrocyclic ligands, which indicate a quite different complexation tendency. In addition, the following steric factors should be taken into consideration. The coordination of acylpyrazolone to the central metal ion is strong owing to the chelate effect. The coordination of the benzocrown ethers to the central metal ion should be restricted by the acylpyrazolones which already coordinated to the central metal ion. The coordination of the crown ether unit in HPMPA15C5 and HPMP-A18C6 is also restricted because it is connected by a carbon chain, which seems not to be long enough.

\section{References}

1. J. Stary, "The Solvent Extraction of Metal Chelates", 1964, Pergamon Press, Oxford.

2. Y. Marcus and A. S. Kertes, "Ion Exchange and Solvent Extraction of Metal Complexes", 1969, Wiley, London.

3. T. Sekine and Y. Hasegawa, "Solvent Extraction in Chemistry", 1977, Marcel Dekker, New York.

4. J. Rydberg, C. Musikas, and G. R. Choppin, "Principles and Practices of Solvent Extraction", 1992, Marcel Dekker New York.

5. A. Roy and K. Nag, J. Inorg. Nucl. Chem., 1978, 40, 331.

6. S. Umetani, M. Matsui, J. Toei, and T. Shigematsu, Anal. Chim. Acta, 1980, 113, 315 .

7. S. Umetani and H. Freiser, Inorg. Chem., 1987, 26, 3179.

8. Y. A. Zolotov, "Macrocyclic Compounds in Analytical Chemistry”, 1997, John Wiley \& Sons, New York.

9. R. M. Izatt, K. Pawlak, J. S. Bradshaw, and R. L. Bruening, Chem. Rev., 1991, 91, 1721.

10. S. Tsurubou, M. Mizutani, Y. Kadota, T. Yamamoto, S. Umetani, T. Sasaki, Q. T. H. Le, and M. Matsui, Anal. Chem., 1995, 67, 1465.

11. S. Tsurubou, S. Umetani, and Y. Komatsu, Anal. Chim Acta, 1999, 394, 317.

12. G. W. Gokel, Chem. Soc. Rev., 1992, 21, 39.

13. H. Tsukube, Coord. Chem. Rev., 1996, 148, 1.

14. X. X. Zhang, A. V. Bordunov, J. S. Bradshaw, N. K. Dalley, X. Kou, and R. M. Izatt, J. Am. Chem. Soc., 1995 , 117,11507

15. F. C. J. M. Van Veggel, W. Verboom, and D. N. Reinhoudt, Chem. Rev., 1994, 94, 279.

16. B. S. Jensen, Acta Chim. Scand., 1959, 13, 1668.

17. S. Umetani, S. Kihara, and M. Matsui, Anal. Chim. Acta, 1990, 232, 293

18. V. S. Ijeri and A. K. Srivastava, J. Chem. Eng. Data, 2002, $47,346$.

19. V. S. Ijeri and A. K. Srivastava, Eur. J. Inorg. Chem., 2001, 943.

20. R. D. Shannon, Acta Crystallogr., 1976, A32, 751. 